\title{
MODEL MANAJEMEN MUTU TERPADU BERBASIS MULTIPLE INTELEGENCE PADA SEKOLAH DASAR UNGGULAN DI KABUPATEN JEPARA
}

\section{Dicky Setiardi, dan Muhammad Misbahul Munir}

Program Studi PGSD, Universitas Islam Nahdlatul Ulama Jepara Email: dickypkn06@.gmail.com

\section{Info Artikel}

\section{Sejarah Artikel:}

Diterima 11 Oktober 2018

Direvisi 7 November 2018

Disetujui 30 November 2018

Keywords:

Integreted Quality Management, Multiple Intelligence, Sekolah

Unggulan

\begin{abstract}
This research is a study of qualitative descriptive. It was carried out at the Jepara Bumi Kartini Primary School. The instrument technique used to collect the data is by interviewing, observing and documentation. The prominent resources is headschool respon, teachers, employees,committee, and the organization of management in primary school of Unggulan Terpadu Bumi Kartini, that collected by essay document, video record/audio tape/MP3 and documetation. The data analysis was carried out at the preliminary study stage, data development and validation stages. The results of the study showed that the application of integrated quality management based on multiple intellegence in the Primary School of Unggulan Bumi Kartini of Jepara Kartini was more aim towards mathematical logical intelligence. Several efforts can be done to implement integreted quality management based on multiple intellegence in other intelligences is by synergizing in the form of good management governance including the availability of human resources, availability of facilities and infrastructure, a conducive environment, updated curriculum, as well as the role of school committees and society participation in implementing integrated quality management based on multiple intellegence, so as to improve the quality of students who will ultimately create excellent schools.
\end{abstract}

\begin{abstract}
Abstrak
Penelitian ini merupakan penelitian yang bersifat deskriptif kualitatif yang bertujuan mengetahui model manajemen mutu terpaduberbasismultipleintelligencepada sekolah unggulan. Penelitian ini dilaksanakan di Sekolah Dasar Unggulan Bumi Kartini Jepara. Teknik yang dipergunakan dalam penggalian data adalah dengan instrumen wawancara, observasi, dan studi dokumentasi sekolah. Sumber data primer berupa jawaban berasal dari kepala sekolah, para guru, para karyawan, para wali murid (komite) serta para pengurus yayasan pengelola Sekolah Dasar Unggulan Terpadu Bumi Kartini yang diperoleh melalui catatan tertulis, melalui perekaman video/audio tape/MP3 dan pengambilan foto. Analisis data dilakukan pada tahap studi pendahuluan, tahap pengembangan dan validasi data.Hasil penelitian menunjukkan penerapan manajemen mutu terpadu berbasis multiple intelligence di Sekolah Dasar Unggulan Bumi Kartini Jepara lebih condong pada kecerdasan logis matematik. Beberapa upaya dapat dilakukan untuk menerapkan manajemen mutu terpadu berbasis multiple intelligence pada kecerdasan lainnya adalah dengan melakukan sinergi berupa tata kelola manajemen yang baik meliputi ketersediaan SDM, ketersediaan sarana dan prasarana, lingkungan kondusif, kurikulum yang sesuai perkembangan zaman, serta peran komite sekolah dan masyarakat dalam partisipasi melaksanakan manajemen mutu terpadu berbasis multiple integence, sehingga mampu meningkatkan kualitas siswa yang pada akhirnya akan menciptakan sekolah unggulan.
\end{abstract}

(C) 2018 Universitas Muria Kudus 


\section{PENDAHULUAN}

Sekolah Dasar Unggulan Terpadu Bumi Kartini adalah salah satu sekolah yang menerapkan kurikulum berbasis multiple intelligencedengan berdasarkan pada pola penyelenggaraan manajemen mutu terpadu. Penerapan manajemen mutu terpadu pada Sekolah dasar unggulan diharapkan dapat mempersiapkan siswa menjadi pribadi berkarakter yang memiliki akhlak mulia, kecerdasan, kemandirian, punya kretifitas, inovatif. Sekolah unggulan merupakan sekolah yang dibentuk untuk menghasilkan lulusan yang unggul, berdaya saing baik secara akdemik maupun non akademik.Di dalam proses untuk menghasilkan lulusan tersebut ditopang oleh beberapa komponen penting antara lain input, kurikulum, guru, tenaga pendidikan, sarana prasarana dan pola manajemen yang baik.

Teori multiple intelligences diawali oleh teori Howard Gardner yang mengarahkan pembelajaran pada pendekatan berdasar potensi masing-masing anak.Merujuk pada hal tersebut maka kecerdasan anak dapat dikembangkan sesuai dengan potensi yang dimiliki. Berpangkal pada teori kecerdasan majemuk, manusia memiliki beberapa bentuk kecerdasan antara lain kecerdasan logis matematik, kecerdasan linguistik, kecerdasan bermusik, kecerdasan visual spasial, kecerdasan intrapersonal (menghargai nilai), jecerdasan interpersonal (kerjasama), kecerdasan kinestetik (terampil) (Gardner 2013).

Observasi awal didapatkan menyatakan bahwa sekarang ini orang tua/masyarakat cenderung lebih memilih sekolah yang "mengintegrasikan" antara pengetahuan umum dan keagamaan seperti yang diterapkan di Sekolah Dasar Unggulan Terpadu Bumi Kartini. Kedua aspek tersebut diterapkan satu paket dalam proses pembelajaran siswa. Dengan demikian diperlukan suatu pengorganisasian kegiatan pembelajaran guna membentuk siswa atau lulusan yang memiliki kecerdasan berdasar potensi masing-masing. Manajemen mutu terpadu berbasis multiple intelligence adalah alternatif yang diterapkan untuk melaksanakan proses pembelajaran yang berorientasi pada kecerdasan siswa.

Berdasarkan latar belakang yang telah diuraikan, dirumuskankan permasalahan yaitu 1) Bagaiamana penerapan manajemen mutu terpadu berbasis multiple integence di Sekolah Dasar Unggulan Terpadu Bumi Kartini Jepara?, 2) Bagaimana evaluasi manajemen mutu terpadu berbasis multiple integence yang diterapkan Sekolah Dasar Unggulan Terpadu Bumi Kartini Jepara?, 3) Seperti apakah model manajemen mutu terpadu berbasis multiple integence yang diterapkan Sekolah Dasar Unggulan Terpadu Bumi Kartini Jepara?

\section{METODE PENELITIAN}

Penelitian ini merupakan penelitian deskriptif kualitatif (Wina Sanjaya, 2013:59).Penelitian ini dilaksanakan di Sekolah Dasar Unggulan Terpadu Bumi Kartini Jepara dengan alamat Jl. Raya Jepara-Bangsri Km. 03 Jepara. Sumber data primer berupa jawaban dari kepala sekolah, para guru dan para karyawan, para orang tua wali murid (komite) serta para pengurus Yayasan pengelola Sekolah Dasar Unggulan Terpadu Bumi Kartini yang diperoleh melalui catatan tertulis, melalui perekaman video/audio tape/MP3 dan pengambilan foto.

Pencatatan sumber data primer dilakukan melalui wawancara dan pengamatan berperan serta. Sumber data sekunder tertulis diperoleh dari sumber buku, kumpulan materi workshop, majalah, surat kabar, sumber dari arsip, dokumen pribadi dan dokumen resmi lainnya. Teknik yang digunakan dalam pengumpulan data antara lain : pengamatan berperan serta, wawancara mendalam, pengamatan (observasi), catatan lapangan dan penelaahan dokumen. Proses analisa data dimulai dengan mengumpulkan semua hal yang diperoleh penulis dari beberapa sumber, kemudian dirangkum, dipilih, dikategorikan dan dimaknai sesuai fokus pokok pembahasan dalam penelitian.

\section{HASIL DAN PEMBAHASAN}

Manajemen Mutu Terpadu Berbasis Multiple Intelegence Di SD Unggulan Terpadu Bumi Kartini Jepara, dimulaiperencanaan berdasarkan visi-misi dan kurikulum sekolah yang direalisasikan pada pengembangan potensi kecerdasan siswa dengan tujuan menghasilkan lulusan yang bermutu.

Manajemen mutu terpadu berbasis multiple intelegence yang diterapkan di Sekolah Dasar Unggulan Terpadu Bumi Kartini meliputi pengembangan potensi logis matematik, berbahasa/ linguistik, musikal, visual-spasial, intra personal dan kinestetik-ragawi. Penerapan manajemen mutu terpadu berbasis multiple intelegenceadalah upaya untuk membentuk siswa dan lulusan yang berkualitas. 


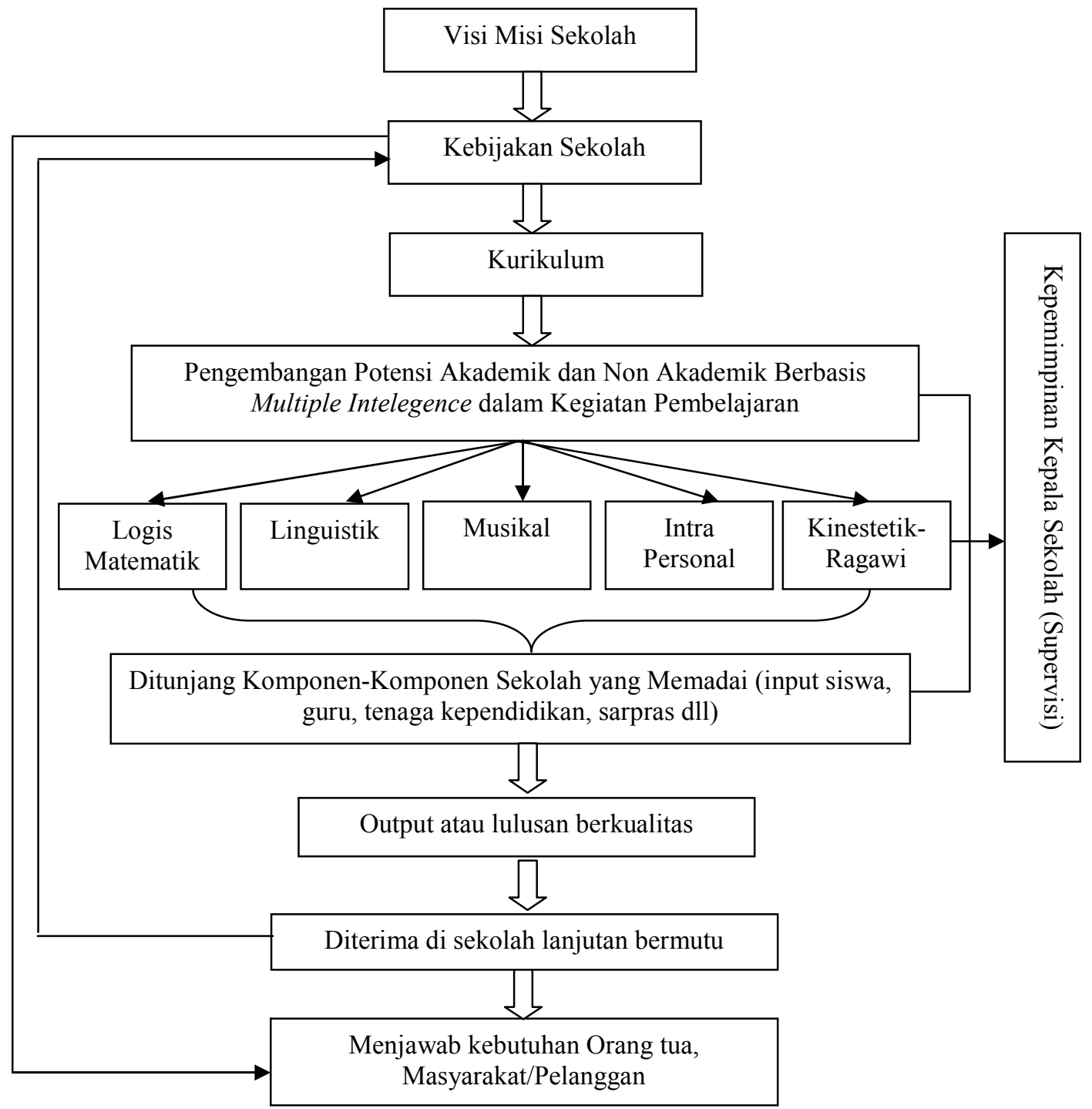

\section{Gambar 1. Mekanisme manajemen mutu terpadu berbasis multiple intelegence di Sekolah Dasar Unggulan Terpadu Bumi Kartini Jepara}

Sekolah Unggulan Terpadu Bumi Kartini Jepara merupakan sekolah swasta yang memperiotaskan potensi siswa berbasis Multiple Intelligence. Sekolah ini juga memberikan kultur Religius dalam pembelajaran. Tujuannya ketika lulus anak bukan hanya mendapatkan ilmu umum tetapi juga ilmu agama yang dipadupadankan dengan soft skill yang dibina. Sekolah Unggulan Terpadu Bumi Kartini Jepara mengedepankan pembelajaran karakter dan pembiasaan sehari-hari sehingga menjadi ciri khas dan keunggulan tersendiri dalam proses pembelajaran serta dengan ditambahkan pelatihan potensi dan minat berbasis Multiple Intelligene, sekolah ini berupaya menghasilkan individu yang memiliki keterampilan dan memiliki ilmu agama yang kuat.

Sekolah Unggulan Terpadu Bumi Kartni Jepara mengembangkan sekolah berbasis Multiple Intelligences dengan dasar bahwa setiap anak memiliki potensi yang berbeda-beda yang harus dikembangkan. Manajemen multiple inteligencessekolah ini berfokus kepada keunggulan masing-masing siswanya dengan demikian dapat optimal mengembangkan kemampuan siswa.

Sekolah ini mengembangkan metode pembelajaran yang memberikan media bagi siswa untuk tidak hanya memenuhi kecerdasan intelektual tetapi dalam setiap aktivitasnya siswa mampu membentuk dan mengembangkan 
Setiardi, Dicky dan Munir, Muh. Misbahul

MODEL MANAJEMEN MUTU TERPADU BERBASIS MULTIPLE INTELEGENCE PADA ...

REFLEKSI EDUKATIKA : Jurnal Ilmiah Kependidikan, Nomor 9, Volume 1, Desember 2018, hlm. 101-106

kecerdasan lainnya. Program unggulan yang variatif menjadi menu keseharian yang menyenangkan dan cenderung berpihak kepada siswa.

Sekolah Unggulan Terpadu Bumi KartniJepara menganut sistem keberagaman anak, tidak ada sistem kelas unggulan. Proses pembelajaran yang diterapkan menghormati semua kemampuan anak dalam bidang apa pun semua anak adalah juara, sekolah ini sangat mengutamakan kenyamanan siswa yang dihargai dengan kecerdasannya masing-masing baik kecerdasan anak bidang akademik dan nonakademik bahkan sekolah ini menghargai karakter yang baik sebagai suatu kecerdasan dan berhak disebut juara bidang karakter yang dimilikinya.Hal tersebut mutlak dilakukan karena persaingan di era global menuntut adanya sumber daya manusia yang unggul. Guru yang cerdas dan kreatif akan menjadi motivasi tersendiri bagi siswanya mau melaksanakan proses belajar dengan penuh semangat (Sasmita, A., dan Fajriyah, K, 2018).

Penerapankonsep multiple intelligences di Sekolah Dasar Unggulan Terpadu BumiKartini Jepara terjabarkan dalam tiga tahap penting yaitu input, proses, dan output. 1) Input, pada tahap input diterapkanMultiple Intelligences Research(MIR)yang bertujuan untuk penentuan kelas dan menentukan kecenderungan gaya belajar siswa pada saat di kelas nantinya. 2) Proses, proses pembelajaran berbasis multiple intelligences yang diterapkan di Sekolah Dasar Unggulan Terpadu Bumi Kartini Jepara menggunakan berbagai macam metode pembelajaran diantaranya environment learning, contectual learning dan sebagainya. Pada pembelajarannya ditemukan banyak kesesuaian antara gaya mengajar guru dan gaya belajar siswa. Hampir seluruh pembelajarannya difokuskan pada kondisi siswa beraktivitas, bukan hanya materi umum saja tetapi materi agama begitu ditekankan dalam sekolahan ini. Harapanya ketika siswa lulus nanti maka siswa mempunyai hardskill untuk melanjutkan ke jenjang berikutnya. 3) Output berupa penilaian, proses pembelajaran. Penilaian yang digunakan adalah penilaian otentik.Penilaian otentik di sekolah ini dilakukan terhadap keseluruhan kompetensi yang telah dipelajari siswa melalui kegiatan pembelajaran dan dalam penilaian ini siswa dinilai dari 3 ranah, yaitu kognitif, psikomotorik dan afektif dalam pengembangan multiple intelligencessiswa.

Evaluasi dari implementasipembelajaran multiple intelligences di Sekolah Dasar
Unggulan Terpadu Bumi Kartini Jepara keseluruhan terletak pada efektivitas kinerja guru dalam mengajar menggunakan pendekatan multiple intelligences dengan melihat sejauh mana seorang guru berhasil dalam menerapkan metode atau gaya mengajar sesuai pendekatan multiple intelligences kepada siswa.

Realisasi konsep multiple intelligences di Sekolah Dasar Unggulan Terpadu Bumi Kartini Jepara ke dalam proses pembelajaran terjabarkan dalam kegiatan sebagai berikut, 1) Pada tahap input sekolah menerapkan test seleksi masuk dalam penerimaan siswa baru. Kemudian siswa yang telah diterima akan mengikuti proses multiple intelligences research (MIR) yang bertujuan untuk penentuan kelas dan menentukan kecenderungan gaya belajar siswa pada saat di kelas nantinya. 2) Proses pembelajaran berbasis multiple intelligence yang diterapkan di Sekolah Unggulan Terpadu Bumi Kartni Jepara menggunakan berbagai macam metode pembelajaran diantaranya environment learning, contectual learning dan sebagainya. Pada pembelajarannya ditemukan banyak kesesuaian antara gaya mengajar guru dan gaya belajar siswa. Hampir seluruh pembelajarannya difokuskan pada kondisi siswa beraktivitas. 3) Proses pembelajaran didalam kelas dan diluar kelas dengan dua guru setiap kelasnya satu guru utama, sekolah ini memberi kebebasan kepada siswa ingin belajar dimana mereka inginkan dan dengan gaya belajar yang mereka inginkan. Operasional sekolah dari jam 07.30-16.00 WIB, siswa diberikanmateri umum dan agama pada proses pembelajaran. Pada hari Jumat siswa mengikuti ekstra kurikuler yang sesuai dengan minat dan bakat.

Penerapan manajemen berbasis multiple intelligences di Sekolah Unggulan Terpadu Bumi Kartni Jepara menggunakan beberapa strategi untuk meningkatkan kecerdasan pada anak, antara lain: 1) Memaksimalkan kegiatan keterampilan berbahasa meliputi keterampilan berbicara, membaca, mendengarkan dan menulis. 2) Melaksanakan pembelajaran musik dengan alat musik yang bersifat tradisional dan modern sehingga siswa peka terhadap musik. 3) Membiasakan siswa untuk belajar berkelompok sebagai upaya menyelesaikan permasalahan secara bersama-sama. 4) Membiasakan siswa untuk bermain, belajar, bergerak dan berolahraga agar memiliki keterampilan motorik naik dalam kegiatan belajar muatan local maupun keolahragaan.

Penerapan strategi pembelajaran berbasis multiple integencedapat memaksimalkan potensi 
Setiardi, Dicky dan Munir, Muh. Misbahul

MODEL MANAJEMEN MUTU TERPADU BERBASIS MULTIPLE INTELEGENCE PADA ...

REFLEKSI EDUKATIKA : Jurnal Ilmiah Kependidikan, Nomor 9, Volume 1, Desember 2018, hlm. 101-106

kecerdasan anak, hal ini terbukti dari prestasi yang telah diraih oleh siswa Sekolah Dasar Unggulan Terpadu Bumi Kartini Jepara di antaranya Juara 4 Kompetisi Matematika Nalaria Realistik (KMNR) yang diselenggarakan Klinik Pendidikan MIPA (KPM) pada tanggal 16 April 2016 di Institut Pertanian Bogor.Keberhasilan dalam meraih prestasi tersebut ditunjang oleh penerapan manajemen berbasis multiple integencedan peran serta aktif seluruh komponen sekolah. Adapun peranan komponen sekolah dapat dijelaskan sebagai berikut, 1) Guru bertugas melaksanakan proses belajar mengajar dengan menyesuaikan gaya belajar anak atau siswa. 2) Kurikulum, memberikan dan menerapkan pembelajaran yang sesuai dengan perkembangan sehingga dapat memunculkan keunggulan di antara sekolah lainnya. 3) Siswa, berpasrtisipasi aktif mengikuti dan mendukung program yang diterapkan oleh Sekolah Dasar Unggulan Terpadu Bumi Kartini Jepara. 4) Kepala Sekolah, menjalankan kepemimpinan dan supervisi serta tindak lanjut terhadap program yang telah dilaksanakan oleh guru, siswa dalam menyelenggarakan proses pembelajaran berbasis multiple integence. 5) Tenaga kependidikan, menjadi actor dan motor penggerak dalam menginventarisasi komponen administrasi dalam manajemen mutu terpadu berbasis multiple integence. 6) Komite sekolah/Orang tua siswa, selalu mengikuti perkembangan penerapan manajemen mutu terpadu berbasis multiple integence dan memberi masukan, kritik yang bersifat membangun terhadap sekolah sebagai tolak ukur dalam menyelenggarakan program sekolah.

Pelaksanaan upaya pemenuhan interaksi belajar yang berpusat pada siswa dan mengutamakan pengembangan kecerdasan yang berujung pada tujuan belajar diharapkan terbentuknya peserta didik dan lulusan yang berkarakter, hal ini karena pembentukan watak dan karakter anak merupakan tugas kewajiban dan tanggungjawab orang dewasa di sekitarnya, pernyataan menguatkan pernyataan bahwa karakter anak berasal dari komitmen semua pihak dalam melaksanakan pendidikan karakter (Maman Rachman, 2017).

Penerapan manajemen mutu terpadu berbasis multiple integenceperlu dibekali prinsip mastery learning, yang mana pembelajaran dioptimalkan dalam bentuk latihan mengerjakan tugas-tugas yang sesungguhnya melalui suatu proses pengalaman langsung menghasilkan (learning by doing) sesuatu yang bermanfaat. Dengan demikian, pembelajaran sangat terintegrasi dengan penilaiannya. Hal ini dapat mendorong terjadinya peningkatan kualitas peserta didik. Proses pembelajaran tidak diarahakan untuk menyiapkan peserta didik untuk menghadapi ujian, tetapi merupakan wahana yang sistematis untuk mengarahkan peserta didik menjadi kompeten.

Pemaparan di atas menunjukan bahwa manajemen mutu terpadu berbasis multiple integence di Sekolah Unggulan Terpadu Bumi Kartni Jepara dapat terselenggara dengan baik karena didukung oleh tata kelola manajemen yang baik meliputi ketersediaan sumber daya manusia, ketersediaan sarana dan prasarana, lingkungan kondusif, kurikulum yang sesuai perkembangan zaman, peran orang tua, komite sekolah dan masyarakat dalam partisipasi melaksanakan manajemen mutu terpadu berbasis multiple integence. Proses penyiapan lulusan yang memiliki daya saing sebagai upaya peningkatan kualitas lulusan agar siap di sekolah lanjutan baik SMP, SMA sampai Perguruan Tinggi. Hal ini sesuai dengan pernyataan bahwa masa mendatang tantangan global menuntut lulusan sekolah menengah atas (SMA) harus dapat bersaing, bergaul di lingkungan internasional yang luas dari berbagai keberagaman baik agama, gender, etnis, sosial ekonomi, sosial budaya dan sebagainya (Su'ad, 2017).

\section{PENUTUP}

Sekolah Unggulan Terpadu Bumi Kartni Jepara menerapkan manajemen mutu terpadu berbasis multiple intelligence yang disesuaikan dengan visi-misi dan kuirkulum sekolah. Pengorganisasian sumber daya manusia, sarana dan prasarana, lingkungan kondusif, kurikulum yang sesuai perkembangan zaman, peran komite sekolah dan masyarakat adalah merupakan tolak ukur keberhasilan dalam melaksanakan manajemen mutu terpadu berbasis multiple integence.

\section{DAFTAR PUSTAKA}

Gardner, Howard. 2013. Multiple Intelligences (Penerjemah: Yelvi Andri Zaimur).Jakarta: Daras Books.

Hamid, A. 2010. Aplikasi Total Quality Management (TQM) PendidikanTinggi Dalam Rangka Pelayanan Pelanggan Mahasiswa Asing di International Islamic University Malaysia (IIUM). Jurnal Manajemen Pendidikan, 1 (2). 
Huriyah, Lilik. Penerapan Total Quality Management (TQM) dalam Peningkatan Mutu Layanan Publik UIN Sunan Ampel Surabaya. JOIES: Journal of Islamic Education Studies, 1 (2) pp. 303-332.

Jabar, A. 2011. Pencapaian Keunggulan Sekolah Di Kota Bandung. Disertasi. Bandung: UPI.

Maman Rachman , dkk. 2017. Pengembangan Model Manajemen Pelatihan Dan Pengembangan Pendidikan Karakter Berlokus Padepokan Karakter. Jurnal Refleksi Edukatika 8 (1).

Mokoginta, H. E. L. 2010. Implementasi Manajemen Mutu Terpadu Dalam Peningkatan Kualitas Pendidikan Tinggi. Artikel Seminar Internasional. APTEKINDO.

Prabowo, S. 2010. Manajemen Mutu Terpadu. Artikel. Diakses tanggal 3 Januari 2017.

Sarah, Pradini Z. 2016. Implementasi Pembelajaran Berbasis Multiple Intelligences Pada Siswa Kelas III Di Sekolah Dasar Jogja Green School Trihanggo Gamping Sleman Yogyakarta. Yogyakarta: UNY.
Sasmita, A., dan Fajriyah, K. 2018. Pengembangan Modul Berbasis Quantum Learning Tema Ekosistem Untuk Kelas V Sekolah Dasar. Jurnal Refleksi Edukatika 8 (2).

Sallis,E. 2011. Manajemen Mutu Terpadu Pendidikan. Peran Strategis Pendidikan di Era Globalisasi Modern. Jogjakarta: IRCiSoD.

Syahza, A. 2010. Penerapan Manajemen Mutu Terpadu pada Dunia Pendidikan. Artikel. Diakses tanggal 3Januari 2013

Su'ad. 2017. Pengembangan Model Manajemen Sekolah Berbasis Multikultural Pada Sekolah Menengah Atas (SMA) Di Eks Karesidenan Pati. Jurnal Refleksi Edukatika 7 (2).

Wahyudi. 2009. Kepemimpinan Kepala Sekolah Dalam Organisasi Pembelajaran (Learning Organization). Bandung: Alfabeta.

Wina, Sanjaya. 2013. Penelitian Pendidikan: Jenis, Metode, dan Prosedur. Jakarta: Kencana. 